of the job in hand. Perhaps, if this is done, true links will be forged so that the inevitable changes we are facing can be tackled in a more positive way.

Incidentally, we do not think that any writer in the $B M 7$ should scoff at any other publication for using "language at times incomprehensible to the reader."

$$
\begin{array}{r}
\text { JAMES SCOBIE } \\
\text { Hon Secretary, } \\
\text { Roehampton Division, BMA } \\
\text { RosemARY YALE } \\
\text { Area Officer, } \\
\text { Wandsworth Social Services Department }
\end{array}
$$

London SW13

SIR,-The hostility of your leading article (3 April, $p$ 790) to the discussion paper on social work training (3 April, p 790) is likely to widen the gulf between our two professions rather than narrow it. A main aim of social work, as the paper makes clear, is the "sustaining of personality," which needs a longer-term perspective on clients and their problems than undergraduate medical education has ever bothered to conceptualise, let alone teach, any more than it has ever taught "the disciplined use of the self" (a concept whose significance you evidently fail to grasp).

Social workers can get little job satisfaction out of arranging case conferences when doctors involved in the case either do not attend, come late and leave early, or merely state their own viewpoint without listening adequately to the contributions of other people present. Like doctors, they are prone to find it easier to do work than to talk about it with others involved in the same task, but (unlike doctors) they are at least trained to realise that it is not always better to do so. In medicine we no longer consult about patients; we merely refer them to our colleagues.

Where social workers are "strangers to their medical colleagues" it is more the fault of the latter than the former, since it is medical men who claim always to be the leaders of caring teams, primary or other. In the present climate it is more important for the social work profession to confront the medical profession and stand its ground than to seek to co-operate with it; for that could only mean capitulation to its authoritarian but myopic insistence on the eradication of short-term problems while ignoring clients' needs for the long-term fostering of whatever personality strengths they may possess.

Finally, for a medical journal such as yours to criticise the discussion paper for the incomprehensibility of its language implies so gross a case of the pot calling the kettle black as to leave me (almost) speechless.

JAMES MATHERS

$\underset{\text { Hereford }}{\text { Hay on }}$

Uterine hypertonus after induction of

SIR,-Dr J E Felmingham and his colleagues (6 March, p 586), commenting upon a case of uterine hypertonus (not defined by the authors) witnessed during labour induction with oral prostaglandin $\mathrm{E}_{2}\left(\mathrm{PGE}_{2}\right)$, may give the impression that this complication had not been reported previously. Admittedly, when
$\mathrm{PGE}_{2}$ is given by mouth, even in relatively high doses (up to $3 \mathrm{mg}$ ) at quite short intervals (30-120 $\mathrm{min})$, the risk of hyperstimulating the myometrium is smaller than when the drug is infused intravenously. Vomiting generally supervenes as soon as effective doses are exceeded, and this seems to provide the oral route with a built-in safety valve. ${ }^{1}$ This view is further strengthened by intrauterine pressure data (unpublished) collated during elective induction of labour at term; with oral $\mathrm{PGE}_{2}$ mean uterine activity was comparable to that of spontaneous and surgically induced labour and was significantly less than when $\mathrm{PGE}_{2}$ was infused by vein.

Nevertheless, investigators using intrauterine tocography have reported an overall incidence of uterine hypertonus during oral $\mathrm{PGE}_{2}$ administration of somewhat less than $1^{\circ}{ }_{0} .{ }^{2}$ It must be stressed that authors have used divergent definitions for hypertonus and that this figure must therefore be taken as an approximation. In two of our own cases $\left(2^{\circ}{ }_{0}\right)$ a transient elevation of basal uterine tone to more than $12 \mathrm{~mm} \mathrm{Hg}$ was registered after a single dose of $0.5 \mathrm{mg} \mathrm{PGE}{ }_{2}$ had been given. One of these episodes caused fetal bradycardia. ${ }^{3}$ Even severe hypertonus $(760 \mathrm{~mm} \mathrm{Hg})$ with marked fetal bradycardia $(60 / \mathrm{min})$ can follow the oral administration of small doses of PGE $_{2}$ as shown by Fraser. ${ }^{4}$ Lauersen and Wilson, ${ }^{5}$ having observed myometrial hyperstimulation after $1 \mathrm{mg} \mathrm{PGE}_{2}$ was given orally, went so far as to recommend the use of an initial dose of $0.25 \mathrm{mg}$ in selected patients to allow proper assessment of uterine sensitivity to the drug.

In other words, although relatively uncommon, uterine hyperstimulation during induction of labour with oral $\mathrm{PGE}_{2}$ has been observed before. Hypertonus is a potential complication of parturition whether an oxytocic is used or not. It follows that, whenever feasible, labour should be monitored by electronic means.

$M$ THIERY

J J AMY

Departments of Obstetrics and Gynaecology,

State University, Ghent, and

Free University, Brussels,

1 Thiery, M, and Amy, J J, in Obstetrics and Gynecology Annual-1976, ed R M Wynn. New York, AppletonCentury-Crofts. In press.

Thiery, M, and Amy, J J, in Prostaglandins and Reproduction, ed S M M Karim, p 195. Lancaster,

Thiery, $\mathbf{M}$, et al, in Prostaglandine in Geburtshilfe und Gynäkologie,

4 Fraser, I S, Lancet, 1974, 2, 162.
5 Lauersen, N H, and Wilson, K H, Obstetrics and Gynecology, 1975, 44, 793 .

\section{Effect of posture on dental anaesthetic mortality}

SIR,-On a previous occasion we commented on the difficulty of drawing valid conclusions from incomplete data of dental anaesthetic mortality. ${ }^{1}$ In spite of this difficulty we have been studying for some years the details of deaths associated with dental treatment with the help of the Registrar General's office and many coroners. At the moment our studies are incomplete and thus not ready for publication, but one point has emerged which seems of sufficient topical importance to justify an early comment. Its significance will be obvious from the conflicting and in some respects ignorant views expressed in the press and reported in the British Dental fournal ${ }^{2}$ follow- ing a recent death in the dental chair. The point may also release practitioners from unjustifiable pressures to use the supine position for general anaesthesia irrespective of the dictates of their own clinical judgment in any particular situation.

In 1974, the latest year for which the Registrar General's returns are available, there were 17 deaths associated with dental treatment and 13 of them were classified as connected with anaesthesia. Of these, nine were in ambulant patients; six of the nine were in dental sur-

\begin{tabular}{|c|c|c|c|}
\hline & Supine & Sitting & $\underset{\text { stated }}{\text { Not }}$ \\
\hline $\begin{array}{ll}\text { Dental surgery } & \ldots \\
\text { Dental centre } & \ldots\end{array}$ & $\frac{5}{-}$ & 1 & $\overline{1}$ \\
\hline Hospital outpatients & 1 & - & 1 \\
\hline
\end{tabular}
geries, one was in a dental centre, and the other two were hospital outpatients. The posture of the patients during the anaesthetic was reported to the coroners as follows:

The relationship of six supine to one sitting is a complete reversal of previous observations. For instance, in 1971, of eight ambulant dental anaesthetic deaths, one patient was anaesthetised in the supine position, five were sitting, and in two cases the posture was not stated. The 1974 findings may have three possible interpretations. Firstly, the observation may be an isolated "freak" of no special significance. Secondly, practitioners may have become sensitive to criticism and failed to report the facts accurately. This seems unlikely, since the campaign to make it obligatory to use the supine posture has been conducted for many years ${ }^{3}$ and there was to our knowledge no special change of circumstances to account for a sudden change of attitude or accuracy of reporting in 1974. Finally, there is the possibility that the supine campaign is being successful and that the dramatic reversal of the postural mortality trend represents a genuine tendency for more practitioners to anaesthetise their patients in the supine position. If indeed this is, even in part, the true explanation then there will continue to be most deaths in that posture which is most commonly employed. Thus Tomlin's comment in $1974^{4}$ that the posture is seldom if ever causally related to the anaesthetic death would appear to be vindicated and the 1974 data may indicate a conversion of dental anaesthetists to the use of the supine position for their patients.

Ivan Curson

King's College Hospital Dental School,
London SE5

Michael Coplans

Royal Dental Hospital,

London WC2

Coplans, M P, and Curson, I, British Medical fournal, 1973, 1, 109.

2 British Dental fournal, 1976, 140, 127.

Bourne, J G, Anaesthesia, 1970, 25, 473.

\section{Pseudomonas aeruginosa in hospital} pharmacies

SIR,-The study by Dr Rosamund M Baird and others (28 February, p 511) demonstrates that hospital pharmacies are often contaminated with Pseudomonas aeruginosa, but no attempt is made to relate this to individual cases of hospital infection. I would like to report briefly an outbreak of $P s$ aeruginosa 
hospital infection which was brought about by contaminated pharmacy "distilled water."

At a London teaching hospital there were 14 new cases of $P s$ aeruginosa respiratory tract infections in August 1968 compared with four or les new cases in each previous month. Nearly all the new cases in previous months were in the intensive care unit but in August there were many cases also on different wards on various floors of the hospital. Several respirators and tracheostomy humidifier were contaminated with Ps aeruginosa, sensitive to polymyxin, gentamicin, and carbenicillin, of the same antibiotic sensitivity and pyocine type as the pseudomonas isolated from the sputum of patients. Most of the infected patients had only recently been attached to a respirator or humidifier and other predisposing factors were usually present, including steroid treatment, respiratory tract disease, and broad-spectrum antibiotic therapy. At the time of the outbreak "distilled water" from the pharmacy was used to fill the humidifier sections of the anaesthetic apparatus. Examination of random sample of four bottles of "distilled water" from the pharmacy showed that all the bottles were heavily contaminated with $P S$ aeruginosa of the same antibiotic sensitivity and pyocine type as that isolated from patients. The plastic bottles which contained the water were also found to be heavily contaminated on their return from the wards. Empty bottles were not sterilised but refilled with "distilled water" in the pharmacy and sent out to the wards. Water collected from a tracheostomy humidifier just before its attachment to one patien yielded growth of the epidemic strain of $P$ aeruginosa and two days later an identical pseudomonas was isolated for the first time from the sputum of the patient. At the end of August all the pharmacy "distilled water" was withdrawn empty plastic bottles disposed of, and only "sterile distilled water" used to fill the humidifier sections of anaesthetic apparatus. In September the number of new $P S$ aeruginosa respiratory infections was reduced to seven and by November the incidence of infection had fallen to four new cases, all in the intensive care unit only.

This outbreak of Ps aeruginosa infections demonstrates the potential hazard to patients of Ps aeruginosa-contaminated pharmacy distilled water. The pharmacy had issued the "distilled water" to the wards without realising the purpose for which it was being used. Many doctors, including anaesthetists, and also nursing staff had not understood the importance of using "sterile distilled water" rather than "distilled water" fo use with anaesthetic apparatus. This erro is probably less likely today because of improved education of staff involved with anaesthetic apparatus. Heating elements are included in modern anaesthetic apparatus which pasteurise the water, helping to reduce the risk of contamination. However, the pasteurisation device is not always used properly, particularly in these days of staff shortages and especially on general wards. Therefore there is still a potential hazard to patients from pseudomonas-contaminated water.

\section{C SHANSON}

Department of Medical Microbiology,

The London

SIR,-In their paper on this subject Dr Rosamund $M$ Baird and her colleagues (28 February, p 511) have justly drawn attention to the presence of pseudomonas contamination in topical preparations and disinfectants dispensed from hospital pharmacies. While agreeing with their conclusions that this problem may be partly overcome by strict attention to hygiene, I feel that more positive action could be taken by using antiseptics and disinfectants which are unlikely to be contaminated by pseudomonads. Ethylenediaminetetraacetic acid (EDTA) has been reported $^{1}$ to sensitise Pseudomonas aeruginosa to a range of antibacterial agents-for example polymyxin, benzalkonium chloride, and parachlorometaxylenol (PCMX), and in addition investigations in these laboratories have shown that a mixture of PCMX and EDTA could not be contaminated with Ps aeruginosa by the method of Bassett et al. ${ }^{2}$

In the light of these findings it seems reasonable to suggest that only those antiseptics and disinfectants which have both a broad spectrum of bactericidal activity and are also known to be resistant to contamination with pseudomonads should be selected for use in hospitals.

R B SMITH

Reckitt and Colman,
Pharmaceutical Division,

Phart

Brown, M R W, Resistance of Pseudomonas aeruginosa. London and New York, Wiley, 1975.

Lancet, 1970, 1, 1188 .

\section{Supervision of repeat prescribing}

SIR,-With reference to the letter from $\mathrm{Dr}$ D L Crombie and others (19 March, p 713) in reply to our article on "The need for supervision in the elderly receiving long-term prescribed medication" (28 February, p 505), contrary to their implied allegations, it must be stated that in no instance was the medication of any patient changed by either of the authors or any of the nursing staff assisting with the survey except after consultation with a member of the practice medical staff (or their locums) and at their direction.

Health Services Research Centre,

S M SHAW

Medical School,
University of Birmingham

\section{IUD and congenital malformation}

SIR, - We were interested to read the paper by Dr Herbert Barrie (28 February, p 488) of two cases of infants with limb reduction deformity born to mothers who were using copper-containing intrauterine contraceptive devices. We present a further case in which this association was observed.

The affected infant was born in 1975 to a 24 year-old Nigerian woman. The mother's first pregnancy in 1971 was legally aborted at eight weeks. In 1974 a Gravigard (Copper-7) IUD wa inserted, but she conceived in January 1975. The pregnancy was uneventful. At 37 weeks gestation the Copper-7 was partly extruded from the cervix and was easily removed. Two days later labour started spontaneously and the child was delivered normally. The male infant cried well at birth. It weighed $2820 \mathrm{~g}$ and the head circumference was $35 \mathrm{~cm}$. The child's head, face, trunk, and right upper limb were normal. The other limbs had severe reduction deformities. The left radius was absent and there were only two fingers on the left hand. Both lower limbs were abnormal: the left had a single slender long bone articulating with the foot, which was markedly dorsiflexed and had only two toes; on the right the femur was angulated, the fibula was absent, and only four metatarsals were present with four toes. The child has made satisfactory progress and gained $1 \mathrm{~kg}$ in the first three months.

The abnormalities described are more extensive than those described by Dr Barrie.
This infant will never achieve a normal gait, and will remain severely handicapped.

\section{P C LEIGHTON \\ D GLYN Evans} SHEILA M WALLIS

Department of Obstetrics and Paediatrics,

St Bartholomew's Hospital,

\section{Pets in hospitals}

SIR,-I was very interested in the article by Mr J E Cooper (20 March, p 698). Until recently insufficient attention had been paid to the role of pets in the treatment and care of patients. ${ }^{1}$ However, I would like to point to a problem which could arise if short-lived pets such as rodents or budgerigars were kept in hospital wards.

It has been suggested that one function of pets in childhood is to provide the child with an introduction to death as a natural process, ${ }^{2}$ but if a child has had sufficient contact with a pet in hospital to become identified with it, perhaps because of long or multiple admissions, then the death of the pet could give rise to much distress and anxiety. The pet has died in hospital and the child may already have anticipated such a fate for himself. This is the more likely if the pet chanced to have prodromal symptoms like those of the child's illness, such as coughing or shortness of breath in asthmatics. Also, if the child has had a hand in caring for the pet he may feel in part responsible for its death and experience considerable guilt. It might be argued that the same feelings would be present if a pet died in the child's home, but there the emotional support available to the child would usually be much greater than that available to him while in hospital.

I would agree with $\mathrm{Mr}$ Cooper, therefore, that pets in hospital can be of value, but I believe that the above factors should be borne in mind when selecting suitable pets, especially for units with a high proportion of longer-term patients. Incidentally, in Tayside at least, the problem is further compounded, as are all other problems relating to children's concept of hospitals, by parents who commonly explain to their children the disappearance of a sick or elderly pet by saying, "He's gone to the hospital."

Alasdair J MacDonald

Ninewells Hospital,

Dundee

Foote, N N, Marriage and Family Living, 1956, 18, Bossard, J H S, and Boll, E S, Sociology of Child Development. New York, Harper, 1966

Del Priore, C, The Child and the Pet. Talk to British Small Animal Veterinary Association, 3 October 1975 (unpublished).

SIR,-Mr J E Cooper's article on this subject (20 March, p 698) is important for paediatricians. There are several reasons why sick children may be helped by having an animal to watch, to caress, or to play with. From our earliest childhood animals are almost brothers. They are also models of mothers and fathers with which we can identify. And were not mammals and birds engaged in mothering and fathering long before man appeared on the scene of evolution? We took it from them. Animals have acted human roles in countless tales, fairy stories, and fables from the begin- 